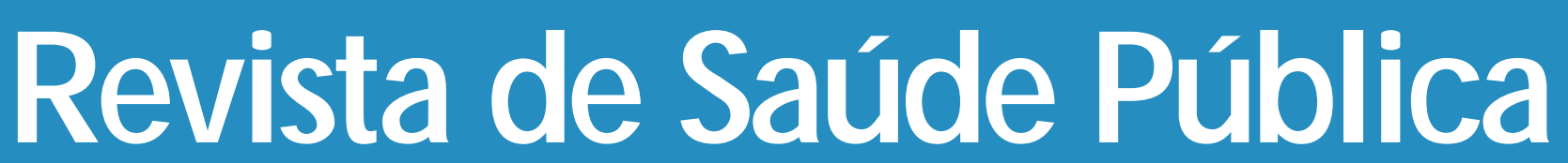

$\begin{array}{lllllll}\mathbf{J} & \mathbf{O} & \mathbf{U} & \mathbf{R} & \mathbf{N} & \mathbf{A} & \mathbf{L}\end{array}$

$0 F$

$\mathbf{P} \mathbf{U}$

B L I C

H E A L T

\title{
Infecção por Trypanosoma cruzi em candidatos a doador de sangue*
}

Trypanosoma cruzi infection in blood donors

Ana M. Bonametti, Adauto Castelo Filho, Luiz R. Ramos, José Luís da S. Baldy e Tiemi Matsuo

Centro de Ciências da Saúde da Universidade Estadual de Londrina. Londrina, PR - Brasil (A. M.B., J.

L.S.B., T.M .), Universidade Federal de São Paulo. São Paulo, SP - Brasil (A C.F., L.R. R.)

BO N AMETTI Ana M. Adauto Castelo Filho, Luiz R. Ramos, José Luís da S. Baldy e Tiemi Matsuo Infecção por Trypanosoma cruzi em candidatos a doador de sangue* Rev. Saúde Pública, 32 (6): 566-71, 1998

(c) Copyright Faculdade de Saúde Pública da USP. Proibida a reprodução mesmo que parcial sem a devida autorização do Editor Científico. Proibida a utilização de matérias para fins comerciais. All rights reserved. 


\title{
Infecção por Trypanosoma cruzi em candidatos a doador de sangue*
}

\section{Trypanosoma cruzi infection in blood donors}

\author{
Ana M. Bonametti, Adauto Castelo Filho, Luiz R. Ramos, José Luís da S. Baldy \\ e Tiemi Matsuo \\ Centro de Ciências da Saúde da Universidade Estadual de Londrina. Londrina, PR - Brasil (A. M.B., J. \\ L.S.B., T.M.), Universidade Federal de São Paulo. São Paulo, SP - Brasil (A C.F., L.R. R.)
}

\begin{abstract}
Introdução
Resumo

A transmissão transfusional da tripanossomíase americana tem-se reduzido no Brasil, com a progressiva ampliação do controle de qualidade do sangue. Nesse sentido, realizou-se pesquisa para avaliar a atual soro-prevalência da infecção por Trypanosoma cruzi em candidatos a doador de sangue em Londrina, Paraná (Brasil), e comparar essa taxa com a encontrada em candidatos a doador estudados em 1958 e 1975, na mesma cidade.
\end{abstract}

Método

Resultados e Conclusão

Introduction

Method

Estudo transversal para determinação da soroprevalência. O imuno-diagnóstico de infecção por Trypanosoma cruzi foi realizado através das técnicas imunoenzimática (ELISA) e imunofluorescência indireta.

A taxa de soroprevalência encontrada foi de 1,3\%. Foi detectada tendência de queda temporal da taxa de positividade dos testes sorológicos para o diagnóstico de infecção por Trypanosoma cruzi nos bancos de sangue do município estudado nos anos de 1958, 1975 e 1995.

Doença de Chagas, epidemiologia. Bancos de sangue. Controle de doenças transmissíveis.

\section{Abstract}

Transmission of American trypanossomiasis by transfusion has been reduced by expansion of control measures of blood quality in Brazil. A research project was, therefore, undertaken to evaluate soropositivity for Trypanosoma cruzi infection on blood donors and to compare this rate with those found in 1958 and 1975 in blood banks.

A transversal study was carried out on blood donors in Londrina, Paraná, Brazil. ELISA and Immunofluorescence were the serological test techniques used in the diagnosis of Trypanosoma cruzi infection.

\footnotetext{
*Parte da tese de doutorado de Ana Maria Bonametti intitulada: "Características da doença de Chagas no Município de Londrina, Paraná, enquanto problema de saúde pública", apresentada à Universidade Federal de São Paulo - Escola Paulista de Medicina, em 1997. Subvencionada pela "International Clinical Epidemiology Network".

Correspondência para/Correspondence to: Ana Maria Bonametti - Rua Roberto Koch, 40 - 86038-440 Londrina, PR - Brasil.

E-mail:bonamet@inbrapenet.com.br.

Edição subvencionada pela FAPESP (Processo n 97/09815-2).

Recebido em 20.10.1997. Reapresentado em 22.4.1998. Aprovado em 11.5.1998.
} 


\section{Results and Conclusion}

A serumprevalence rate of $1.3 \%$ was found with a tendency for positive serum findings for Trypanosoma cruzi infection on blood donors to decrease over Aime (1958, 1975, and 1995).

Chagas disease, epidemiology. Blood banks. Communicable disease control.

\section{INTRO D U ÇÃO}

A transfusão sangüínea tem adquirido enorme relevância na epidemiologia da doença de Chagas, tendo-se transformado na principal via de transmissão na zona urbana, na qual residem $70 \%$ da população das Américass ${ }^{7,28}$. Atualmente, a transfusão de sangue constitui o segundo mais freqüente mecanismo de transmissão de Trypanosoma cruz ${ }^{12,23,24}$.

Segundo Dias ${ }^{8}$, a doença de Chagas transfusional tem importância significativa em toda a área endêmica. $\mathrm{O}$ problema foi concretamente estudado a partir de 1944 e tecnicamente equacionado em 1951. Até a década de 80 , porém, muitos países endêmicos sequer discutiram a transmissão transfusional ou suspeitavam claramente de sua ocorrência ${ }^{8}$.

O problema da doença de Chagas transfusional torna-se mais grave quando se verifica que número enorme de transfusões de sangue é realizado sem indicação clínica e sem respaldo laboratorial seguro; a esses fatos associa-se a crescente urbanização da endemia chagásica em toda a área latino-americana, resultante de profundas transformações econômico-sociais - que transformaram a migração rural-urbana em alternativa e estratégia de sobrevivência, vinculadas também ao papel do migrante enquanto componente da força de trabalho, no processo de acumulação do capital ${ }^{15}$.

Com exceção dos derivados sangüíneos, em cujo preparo são submetidos a processos físico-químicos de esterilização (tais como a albumina e a imunoglobulina humana normal ou gamaglobulina), todos os componentes sangüíneos podem transmitir a infecção por Trypanosoma $\mathrm{cruzi}^{27}$. O risco técnico de um receptor infectar-se a partir de transfusão isolada de componentes hemoterápicos de doador chagásico varia de 12,5 a $27 \%{ }^{4,9,10}$. Segundo Ferreira e col. ${ }^{11}$ (1996), a prevalência da infecção por Trypanosoma cruzi em doadores de sangue na América Latina tem oscilado entre $2 \%$ a $4 \%$, com valores extremos próximos a zero, em inquéritos realizados recentemente no Uruguai e em São Paulo-SP, e valores máximos acima de $60 \%$ em algumas regiões da Bolívia. No Brasil, inquéritos soroepidemiológicos feitos nos últimos anos evidenciaram prevalência média para o País em torno de $0,7 \%$, com tendência a queda, sen- do mais altos os índices observados em regiões de Goiás (cerca de 5\%) $)^{11,13}$.

A ampla revisão, realizada por Schmunis ${ }^{21}$ (1991), inclui numerosos inquéritos realizados na década anterior em bancos de sangue de todo o Continente Americano, registrando-se prevalências que variam de zero a $63 \%$, com média de aproximadamente $3 \%$.

Segundo Souza e col..$^{25}$ (1997), o programa nacional relativo a sangue e hemoderivados, implantado no Brasil a partir de 1980, - que já conta com aproximadamente três centenas de unidades de hemoterapia instaladas em todos os Estados da Federação - foi responsável por 30\% das 4.695 .000 transfusões estimadas para o ano de 1991 e por 1.038 .174 das realizadas em 1993. Apesar do sensível sucesso do programa, no decorrer de uma década não se registrou aumento da cobertura nos anos 1992 e 1993.

A análise conjunta dos dados coletados pela Coordenação Nacional de Sangue e Hemoderivados do Ministério da Saúde, bem como dos coletados por especialistas, coloca em evidência dois pontos básicos: o desnível da hemoterapia praticada no Brasil: de extremamente primária (como se verifica na maioria das cidades pequenas), até bastante complexa e evoluída (como a praticada pela maioria dos hemocentros e por alguns serviços especializados); a discreta participação do Sistema Hemocentro, que em 1988 possuía 27 unidades e que, em 1991, atingiu pouco mais de uma centena em todo o País ${ }^{16}$.

Não obstante, em termos de população, os dados desse inquérito indicam que o grau de cobertura e a qualidade da hemoterapia tendem a melhorar de ano para ano nos centros urbanos maiores, onde se faz a grande maioria das transfusões do País, reduzindo assim, progressivamente, a possibilidade de transmissão, por transfusão de sangue, da doença de Chagas e de outras infecções ${ }^{16}$. Em 1982, em torno de $6,5 \%$ dos candidatos a doador de sangue eram infectados por Trypanosoma cruzi; em 1992, essa taxa caiu para $1 \%$. A soroprevalência da infecção por Trypanosoma cruzi em indivíduos com sete a 14 anos de idade alcançava 4,2\% em 1980, enquanto em 1994 era de apenas $0,15 \%$, indicando que a ocorrência de novos casos infectados nessa faixa etária diminuiu cerca de $95 \%$.

A transmissão transfusional da tripanossomíase 
americana tem-se reduzido no Brasil, com a progressiva ampliação do controle de qualidade do sangue, que hoje deve alcançar cerca de 70 a $85 \%$ do total de sangue transfundido no País ${ }^{6,7}$.

Constitui objetivo do presente estudo avaliar a prevalência da infecção por Trypanosoma cruzi - por intermédio de testes sorológicos (ELISA e imunofluorescência indireta (IFI)) - em candidatos a doador de sangue e comparar a atual taxa de prevalência da infecção com a encontrada em candidatos a doador de sangue estudados em 1958 e 1975.

\section{MÉTO DO}

O delineamento adotado para esta investigação foi o transversal, para determinação da soroprevalência da infecção por Trypanosoma cruzi em candidatos a doador de sangue do Hemocentro Regional de Londrina, Paraná.

A amostra dos candidatos a doador de sangue foi obtida, de forma seriada, no Hemocentro Regional de Londrina, Paraná, no período de 5 de setembro a 9 de dezembro de 1995, com a coleta de sangue venoso de mil candidatos a doador consecutivos, caracterizando uma amostra de conveniência. A coleta de sangue dos candidatos a doador foi feita por punção venosa, usando seringas e agulhas descartáveis. Os exames sorológicos foram realizados no laboratório clínico do Hospital Universitário Regional do Norte do Paraná, Londrina, e as técnicas utilizadas foram a imunofluorescência indireta (IFI) e o teste imunoenzimático (ELISA). Foram considerados como sororreagentes os doadores com uma ou ambas as reações positivas.

Cada doador respondeu a um questionário com informações sobre idade, sexo, residência e naturalidade.

Foi utilizada estatística descritiva para cálculo das médias e desvios-padrão das idades dos candidatos a doador, intervalos de confiança de proporções e distribuição das variáveis sob forma de tabelas. Para a comparação da prevalência da positividade das reações sorológicas para o diagnóstico da infecção por Trypanosoma cruzi em candidatos a doador de sangue do Município de Londrina, em amostras obtidas nos anos 1958, 1975 e 1995, foi utilizado o teste do Qui-Quadrado para tendência. Para a comparação das proporções relativas à positividade da infecção por Trypanosoma cruzi em candidatos a doador de sangue naturais de Londrina e nos nascidos em outros municípios do
Estado do Paraná e de outros Estados do Brasil, utilizou-se o teste exato de Fisher. O nível de significância adotado foi o de $5 \%(a=0,05)$ e em todos os testes estatísticos foram apresentados o valor calculado de $\mathbf{p}$.

\section{RESU LTADO $S$}

A idade dos candidatos a doador de sangue variou de 18 a 59 anos, com média de 32,10 \pm 9,59 anos. A maioria dos candidatos a doador de sangue era do sexo masculino $(82,9 \%)$ e residia na zona urbana do Município de Londrina (95,0\%). Quanto à naturalidade, observou-se que $337(33,70 \%)$ dos candidatos a doador de sangue eram nascidos no Município de Londrina, enquanto que os restantes $663(66,3 \%)$ eram migrantes.

$\mathrm{Na}$ Tabela 1, do total de mil candidatos a doador de sangue, apenas 13(1,3\%) apresentavam pelo menos uma das reações positivas para infecção por Trypanosoma cruzi (ELISA e/ou IFI).

$\mathrm{Na}$ comparação entre os candidatos a doador de sangue sororreagentes naturais de Londrina (nãomigrantes) com os sororreagentes nascidos em outros municípios do Estado do Paraná ou em outros municípios de outros Estados do Brasil (migrantes), houve diferença estatisticamente significativa ( $\mathrm{p}<0,0001)$, ou seja, a prevalência de soropositividade para infecção por Trypanosoma cruzi nos candidatos a doador de sangue migrantes foi maior do que a soropositividade observada em candidatos a doador nascidos no Município de Londrina, Paraná (Tabela 2).

A comparação da prevalência da positividade dos

Tabela 1 - Distribuição dos candidatos a doador de sangue de acordo com o resultado dos testes sorológicos (IFI e ELISA) para o diagnóstico de infecção por Trypanosoma cruzi.

\begin{tabular}{lrrr}
\hline IFI e/ou ELISA & $\mathrm{N}$ & $\%$ & IC (95\%) \\
Reagentes & 13 & 1,3 & $0,7-2,2$ \\
Não reagentes & 987 & 98,7 & $97,8-99,3$ \\
\hline Total & 1.000 & 100,0 & \\
\hline IFI - Imunofluorescência indireta & & \\
IC - Intervalo de confiança &
\end{tabular}

Tabela 2 - Distribuição dos candidatos a doador de sangue segundo a naturalidade e o resultado dos testes sorológicos (ELISA e/ou IFI) para o diagnóstico da infecção por Trypanosoma cruzi.

\begin{tabular}{|c|c|c|c|c|c|c|c|}
\hline \multirow{3}{*}{ ELISA e/ou IFI } & \multicolumn{6}{|c|}{ N aturalidade } & \multirow[b]{2}{*}{ Total } \\
\hline & \multicolumn{3}{|c|}{ Londrina } & \multicolumn{3}{|c|}{ O utros municípios } & \\
\hline & $\mathrm{N} \underline{0}$ & $\%$ & IC (95\%) & $\mathrm{N} \stackrel{0}{0}$ & $\%$ & IC (95\%) & \\
\hline Reagentes & 0 & 0,0 & $0,0-1,1$ & 13 & 2,0 & $1,1-3,3$ & 13 \\
\hline $\mathrm{N}$ ão reagentes & 338 & 100,0 & $98,6-100,0$ & 649 & 98,0 & $96,6-98,9$ & 987 \\
\hline Total & 338 & 100,0 & & 662 & 100,0 & 100,0 & \\
\hline
\end{tabular}


testes sorológicos para o diagnóstico da infecção por Trypanosoma cruzi em candidatos a doador de sangue, residentes na cidade de Londrina, nos anos de $1958(6,9 \%), 1975(7,5 \%)$ e 1995 (1,3\%) revelou diferença significativa, ou seja, a positividade encontrada em 1995 foi menor do que a observada nos anos de 1958 e de 1975 (p<0,0001) (Tabela 3).

\section{DISCUSSÃO}

A taxa de positividade dos testes sorológicos para o diagnóstico da infecção por Trypanosoma cruzi em candidatos a doador de sangue foi de 1,3\%, ou seja, foram encontrados 13 indivíduos soro-positivos entre os mil candidatos a doador avaliados. Esse índice de positividade é semelhante à atual taxa média encontrada em doadores de sangue de todo o País, que, segundo Moraes-Souza e col. ${ }^{17}$, é de aproximadamente $1 \%$.

Do total dos mil candidatos estudados, 337 $(33,7 \%)$ nasceram no Município de Londrina, 63,3\% nasceram em outras cidades do Estado do Paraná $(44,7 \%)$ ou do Brasil $(21,6 \%)$. O fato de a maioria dos candidatos a doador de sangue ter sido constituída por migrantes, sugere que os migrantes, constituem parte significativa da população geral do município, na faixa etária dos adultos. De acordo com o Censo de 1980 do IBGE, 39,2\% da população do Município de Londrina eram migrantes ${ }^{26}$. Esse fato é importante, porque no inquérito sorológico realizado no período de 1976 a 1979 na população geral rural do município - quando o índice de positividade para a infecção por Trypanosoma cruzi foi de 3,7\% ${ }^{14}$ - certamente uma parcela significativa dos indivíduos soropositivos eram migrantes, tendo adquirido a infecção nos locais de origem e não no Município de Londrina.

Todos os 13 candidatos a doador de sangue soropositivos eram migrantes, tendo a análise esta- tística revelado diferença significativa quando foi feita a comparação dessa taxa de soropositividade com a encontrada nos candidatos a doador de sangue nascidos no Município de Londrina ( $\mathrm{p}<0,0001$ ).

Segundo Baldy ${ }^{1}$ e Baldy e col. ${ }^{2}$, os dados por eles obtidos em 1975, comparados com os de Brofman ${ }^{3} \mathrm{e}$ os de Queiroz e Pascual ${ }^{19}$, de 1958, indicaram que a prevalência da infecção chagásica em Londrina, avaliada por intermédio de reações sorológicas em bancos de sangue, não sofreu modificação significativa naquele período de 17 anos.

No entanto, a comparação da taxa de positividade da infecção por Trypanosoma cruzi encontrada no presente estudo com as obtidas em 1958 e 1975 revelou tendência a uma diminuição temporal dessas taxas ( $\mathrm{p}<0,0001)$, ou seja, a taxa de soropositividade atual para a infecção por Trypanosoma cruzi é menor do que as encontradas nos anos de 1958 e 1975. Nesses dois estudos, de 1958 e 1975, a taxa de candidatos a doador residentes em zona rural era maior, muitos deles residentes em várias cidades do Paraná, enquanto a amostra estudada na presente pesquisa foi constituída por pessoas residentes exclusivamente no Município de Londrina, a maioria na zona urbana.

Em estudo mais recente, de 1985, Pontello e col. ${ }^{18}$ realizaram testes sorológicos para o diagnóstico da infecção por Trypanosoma cruzi em 1.977 candidatos a doador de sangue de 33 cidades do Estado do Paraná, no período de janeiro de 1980 a dezembro de 1983 , sendo de $7,2 \%$ a taxa de positividade encontrada. Os autores ressaltam que houve grande variação de positividade nos 33 municípios avaliados (0 a 36,4\%). Nesse estudo foram incluídos apenas 50 candidatos a doador residentes em dois distritos rurais de Londrina e o índice de positividade desse grupo foi nulo.

Reiche e col. ${ }^{20}$ avaliaram, em 1996, 45.774 amostras de soro de candidatos a doador de sangue do Hemocentro Regional de Londrina, no período de

Tabela 3 - Resultados dos inquéritos sorológicos para infecção por Trypanosoma cruzi em candidatos a doador de sangue da cidade de Londrina, nos anos 1958, 1975 e 1995.

\begin{tabular}{|c|c|c|c|c|c|c|}
\hline Autores & Ano & Técnicas & $\begin{array}{c}\mathrm{N} \mathrm{da} \\
\text { amostra }\end{array}$ & $\begin{array}{l}\mathrm{N} \text { de soro- } \\
\text { positivos }\end{array}$ & $\begin{array}{l}\mathrm{N} \text { de soro } \\
\text { negativos }\end{array}$ & $\begin{array}{c}\text { Prevalência(\%) } \\
\text { IC }(95 \%)\end{array}$ \\
\hline Queiróz e Pascual19 & 1958 & $\mathrm{FC}$ & 1.330 & 92 & 1.238 & $\begin{array}{r}6,9 \\
5,6-8,4\end{array}$ \\
\hline Baldy e col. ${ }^{2}$ & 1975 & $\mathrm{FC} / \mathrm{IFI}$ & 4.500 & 337 & 4.163 & $\begin{array}{r}7,5 \\
6,7-8,3\end{array}$ \\
\hline Bonametti (presente estudo) & 1995 & IFI / ELISA & 1.000 & 13 & 987 & $\begin{array}{r}1,3 \\
0,7-2,2\end{array}$ \\
\hline
\end{tabular}

Qui-quadrado para tendência linear $=22,588(2 \mathrm{gl} ; 5 \%) \mathrm{p}<0,0001$

FC - Fixação de complemento

IFI - Imunofluorescência indireta 
maio de 1990 a dezembro de 1994, através de duas técnicas sorológicas para o diagnóstico de infecção por Trypanosoma cruzi (inibição da hemaglutinação e imunofluorescência indireta), tendo sido igual a $1,4 \%$ a taxa de positividade encontrada, índice semelhante ao obtido no presente estudo, e também semelhante ao índice médio nacional de positividade dos testes sorológicos para o diagnóstico de tripanossomíase americana em candidatos a doador de sangue.

Segundo Dias ${ }^{6,7}$, se conseguida e mantida a interrupção da transmissão vetorial, pode-se prever redução progressiva da transmissão transfusional. De acordo com esse autor, a transmissão transfusional tende a ser cada vez mais controlada, na medida em que o sistema de saúde melhore a qualidade do sangue, particularmente por causa do temor da AIDS. Por outro lado, com a redução geral da incidência da tripanossomíase americana, torna-se cada vez menos freqüente o ingresso de chagásicos no grupo etário de pessoas que doam sangue, em paralelo com a saída progressiva de infectados do rol de doadores, por idade ou por morbimortalidade devida à doença de Chagas. Se atualmente estima-se haver por volta de 50.000 chagásicos como doadores potenciais ( $1 \%$ de prevalência), esse número deve cair para a metade ou menos nos próximos dez anos, sabendo-se que a prevalência de candidatos a doador infectados por Trypanosoma cruzi já é hoje significativamente mais baixa em pessoas com 20 a 30 anos de idade, em comparação com faixas etárias superiores ${ }^{6,7}$.

De acordo com Schmunis ${ }^{22}$, a sorologia para tripanossomíase americana em candidatos a doador de sangue é obrigatória em vários países latino-americanos: Argentina, Brasil, Chile (somente em áreas endêmicas), Honduras, Paraguai, Uruguai e Venezuela. Em outros, também se estabeleceu como rotina esse procedimento (Equador). Nota-se que o número de testes sorológicos realizados nas Américas está aumentando ano a ano; no entanto, mesmo nos países onde a realização de testes sorológicos nos candidatos a doador é obrigatória, o controle governamental é ainda limitado ${ }^{22}$. De qualquer maneira, a epidemia de AIDS vem conscientizando as autoridades e o público em geral sobre a importância das medidas de controle da hemoterapia. A promoção da doação altruísta, a proibição da venda de sangue e a anamnese dos candidatos a doador, para descartar os de alto risco, antes de realizar os exames sorológicos, têm contribuído decididamente para melhorar a qualidade do sangue usado em transfusões. Com todas essas medidas postas em prática, o resultado deverá ser a redução da transmissão transfusional da tripanossomíase americana ${ }^{22}$.

\section{REFERÊN CIAS}

1. BALDY, J.L.S. Doença de Chagas por transfusão de sangue em Londrina. Semina, 1: 33-6, 1978.

2. BALDY, J.L.S.; TAKAOKA, L.; PEREIRA, J.D.; CALIXTO, A.A.; DUARTE, E.F. Prevalência da infecção por Trypanosoma cruzi em 1975, em dois bancos de sangue de Londrina, Paraná, Brasil. Rev Saúde Pública, 12: 409-16, 1978.

3. BROFMAN, S. Incidência da doença de Chagas no Norte do Paraná. Arq. Bras. Cardiol., 11: 209-10, 1958.

4. CASTRO, M.L.R.B. Transmissão da infecção chagásica em áreas urbanas. Rev. Soc. Bras. Med. Trop., 27 (Supl.4): 136-8, 1994.

5. CHAGAS sucess in Brazil and Colombia. TDR News, 49: 3-4, 1996.

6. DIAS, J.C.P. Doença de Chagas no Brasil: situação atual e perspectivas. Inf. Epidemiol. SUS, 17-25, 1992.

7. DIAS, J.C.P. Doença de Chagas no Brasil: situação atual e perspectivas. In: Costa, M.F.F. L. \& Souza, R.P. Qualidade de vida: compromisso histórico da epidemiologia. Belo Horizonte, Coopmed/Abrasco, 1994. p.37-43.
8. DIAS, J.P.D. Estratégias e perspectivas atuais da consolidação do controle dos vetores na etapa de vigilância epidemiológica. Rev. Soc. Bras. Med. Trop., 27(Supl. 2): 63-6, 1994.

9. DIAS, J.C.P. Doença de Chagas: epidemiologia e prevenção. Arq. Bras. Cardiol., 63: 451-5, 1994.

10. DIAS, J.C.P.; LOYOLA, C.C.P.; BRENER, S. Doença de Chagas em Minas Gerais: situação atual e perspectivas. Rev. Bras. Malariol. Doenças Trop., 37: 7-28, 1985.

11. FERREIRA, M.S.; LOPES, E.R.; CHAPADEIRO, E.; DIAS, J.C.P.; OSTERMAYER, A.L. Doença de Chagas. In: Veronesi, R. \& Focaccia, R. ed. Tratado de infectologia. São Paulo, Atheneu, 1996. p. 1175 - 213.

12. LANA, M. \& TAFURI, W.L. Trypanosoma cruzi. In: Neves, D.P.; Melo, A.L.; Genro, O.; Linardi, P.M. Parasitologia humana. $9^{\mathrm{a}}$ ed. São Paulo, Atheneu, 1995. p. 82-114.

13. LIMA E COSTA, M.F. Investigação epidemiológica de endemias no Brasil. [Editorial] Cad. Saúde Pública, 10(Supl.2): 240, 1994. 
14. MINISTÉRIO DA SAÚDE. Superintendência de Campanhas de Saúde Pública. Diretoria Regional do Paraná. Inquérito sorológico (Doença de Chagas) no Estado do Paraná (1976 a 1979); Relatório, Curitiba, 1979.

15. MINISTÉRIO DA SAÚDE. Superintendência de Campanhas de Saúde Pública. Doença de Chagas. Brasília, 1989 (Textos de Apoio).

16. MORAES-SOUZA, H. Doença de Chagas transfusional no Brasil. Rev. Soc. Bras. Med. Trop., 25(Supl. 3): 31-2, 1992.

17. MORAES-SOUZA, H.; WANDERLEY, D.M.V.; BRENER, S.; NASCIMENTO, R.D.; ANTUNES, C.M.F.; DIAS, J.C.P. Hemoterapia e doença de Chagas transfusional no Brasil. Bol. Of. Sanit. Panam., 11:406-18, 1994.

18. PONTELLO, R.; REICHE, E.M.V.; CABRERA, E.J. Prevalência da infecção por Trypanosoma cruzi, Treponema pallidum e vírus da hepatite $\mathrm{B}$, no período de 1980 a 1983, avaliada através de testes sorológicos, em 1977 candidatos a doadores de sangue de 33 cidades do Estado do Paraná. Semina, 6: 87- 92, 1985.

19. QUEIROZ, J.A. \& PASCUAL, J. Contribuição ao estudo da doença de Chagas no Norte do Paraná. Rev. Med. Paraná, 27: 27-30, 1958 .

20. REICHE, E.M.V.; INOUYE, M.M.Z.; PONTELLO, R.; MORIMOTO, H.K.; ITOW JANKEVICIUS, S.; MATSUO, T.; JANKEVICIUS, J.V. Seropositivity for anti-Trypanosoma cruzi antibodies among blood donors of the "Hospital Universitário Regional do Norte do Paraná", Londrina, Brazil. Rev. Inst. Med. Trop. S. Paulo, 38: 233 - 40, 1996.
21. SCHMUNIS, G.A.Trypanosoma cruzi, the etiologic agent of Chagas disease: Status in the blood supply in endemic and nonendemic countries. Transfusion, 31: 547- 57, 1991.

22. SCHMUNIS, G.A. Tripanossomíase americana: seu impacto nas Américas e perspectivas de eliminação. In: Dias, J.C.P. \& Coura, J.R. Clínica e terapêutica da Doença de Chagas. Rio de Janeiro, FioCruz, 1997. p. 11-23.

23. SIQUEIRA-BATISTA, R.; STORINO, R.A.; MIRANDA FILHO, N.; CHIGA, A.L.V.; QUINTAS, L.E.M. Doença de Chagas: histórico e epidemiologia. ARS Cvrandi Cardiol., 15: 8-14, 1993.

24. SIQUEIRA-BATISTA, R.; HUGGINS, D.W.; MEDEIROS, L.B.; FERREIRA, K.P.T.; QUINTAS, L.E.M.; CORRÊA, A.D. Perspectivas. In: Siqueira-Batista, R.; Corrêa, A.D.; Huggins, D.W. Moléstia de Chagas. Rio de Janeiro, Cultura Médica, 1996. p. 172-80.

25. SOUZA, H.M.; RAMIREZ, L.E.; BORDIN, J.O. Doença de Chagas transfusional: medidas de controle. In: Dias, J.C.P. \& Coura, J. R. Clínica e terapêutica da Doença de Chagas. Rio de Janeiro, FioCruz, 1997. p. 429 - 43.

26. UNIVERSIDADE ESTADUAL DE LONDRINA. Projeto UNI: uma nova iniciativa na educação dos profissionais de saúde: união com a comunidade. Londrina, 1992.

27. WENDEL NETO, S. Reações adversas das transfusões. In: Verrastro, T.; Lorenzi, T.F.; Wendel Neto, S. Hematologia e hemoterapia: fundamentos de morfologia, fisiologia, patologia e clínica. São Paulo, Atheneu, 1996. p.279 - 89.

28. WORLD HEALTH ORGANIZATION. Control of Chagas disease. Geneva, 1991 (WHO Technical Report Series, 811). 